\title{
Estudo da qualidade do agregado miúdo utilizado na construção civil
}

\section{Quality study of the small aggregate used in civil construction}

Estudio de calidad del pequeño árido utilizado en construcción civil

Rebeka Manuela Lobo Sousa

ORCID: https://orcid.org/0000-0002-8195-6447 Instituto Federal de Educação, Ciência e Tecnologia do Piauí, Brasil E-mail:rebekamanuela28@gmail.com

Paulysendra Felipe Silva

ORCID: https://orcid.org/0000-0002-0129-8772 Instituto Federal de Educação, Ciência e Tecnologia do Piauí, Brasil E-mail: sendra_102@hotmail.com

Francisca das Chagas Oliveira

ORCID: https://orcid.org/0000-0002-6262-9125 Instituto Federal de Educação, Ciência e Tecnologia do Piauí, Brasil E-mail: francisca.mat@hotmail.com

Heitor Fernandes Sousa

ORCID: https://orcid.org/0000-0002-7617-4117 Instituto Federal de Educação, Ciência e Tecnologia do Piauí, Brasil E-mail: heitorfcivil@gmail.com

Phillype Dowglas Lopes

ORCID: https://orcid.org/0000-0002-4103-3883 Instituto Federal de Educação, Ciência e Tecnologia do Piaú, Brasil

E-mail: eng.phillype@ @otmail.com

Francisco Arlon De Oliveira Chaves ORCID: https://orcid.org/0000-0002-5503-0923

Centro Universitário Santo Agostinho, Brasil E-mail: arlonoliv@hotmail.com

Milton de Sousa Falcão

ORCID: https://orcid.org/0000-0002-2560-8114 Universidade Federal do Piauí, Brasil

E-mail: sf.milton@gmail.com

Gilvan Moreira da Paz

ORCID: https://orcid.org/0000-0002-6849-0320 Instituto Federal de Educação, Ciência e Tecnologia do Piauí, Brasil E-mail:gilvan@ifpi.edu.br

Roberto Arruda Lima Soares

ORCID: https://orcid.org/0000-0003-1892-7499 Instituto Federal de Educação, Ciência e Tecnologia do Piauí, Brasil E-mail: robertoarruda@ifpi.edu.br

\begin{abstract}
Resumo
O agregado miúdo na sua composição natural pode apresentar diversas propriedades que podem ser alteradas em virtude do tipo e quantidade dos componentes envolvidos. Para identificar tais propriedades é necessário que seja feito experimentos utilizando métodos e equipamentos específicos. Diante deste contexto, este trabalho tem a finalidade de fazer, analise nas amostras de jazidas de agregados miúdos para verificar a qualidade deste material. O estudo terá como ponto de partida ensaios para a definição granulométrica, florescência de raio X (FRX) e difração de reio X (DRX). Após a execução dos ensaios laboratoriais, serão montadas as respectivas tabelas dos resultados da granulometria e FRX, um gráfico com resultados do ensaio de DRX e das curvas granulométricas para cada amostra. Com base nos resultados experimentais obtidos de acordo com as normas vigentes, serão efetuadas as análises. Na conclusão deste artigo pretende-se definir a qualidade dos três tipos de agregados miúdos é a mais adequada para cada especialidade na construção civil.
\end{abstract}

Palavras-chave: Agregado Miúdo; Granulometria; FRX; DRX.

\section{Abstract}

The kid aggregate in its natural composition can have several properties that can be altered by virtue of the type and quantity of the components involved. To identify such properties, it is necessary to do experiments using specific methods and equipment. Given this context, this work aims to do, analyze in the samples of deposits of aggregates kids to verify the quality of this material. The study will have as a starting point test for the granulometric definition, $\mathrm{X}$-ray flowering (FRX) and king X diffraction (XRD). After the laboratory tests, the respective graph scans will be assembled a graph with results of the XRD assay and the granulometric curves for each sample. Based on the 
experimental results obtained in accordance with the current standards, the analyses will be carried out. At the conclusion of this article, we intend to define the quality of the three types of aggregates kids is the most suitable for each specialty in construction.

Keywords: Kid Aggregate; Granulometry; FRX; DRX.

\section{Resumen}

El agregado fino en su composición natural puede presentar varias propiedades que pueden alterarse por el tipo y cantidad de los componentes involucrados. Para identificar tales propiedades, es necesario realizar experimentos utilizando métodos y equipos específicos. Ante este contexto, este trabajo tiene como objetivo analizar las muestras de depósitos de agregados finos para verificar la calidad de este material. El estudio tendrá como punto de partida las pruebas de definición del tamaño de partículas, fluorescencia de rayos X (FRX) y difracción de rayos X (XRD). Luego de realizar las pruebas de laboratorio, se ensamblarán las respectivas tablas con los resultados de la granulometría y FRX, una gráfica con los resultados de la prueba XRD y las curvas granulométricas para cada muestra. En base a los resultados experimentales obtenidos de acuerdo con las normas vigentes, se realizarán los análisis. En la conclusión de este artículo pretendemos definir la calidad de los tres tipos de áridos finos, que es la más adecuada para cada especialidad en construcción civil.

Palabras clave: Agregado pequeño; Granulometría; FRX; DRX.

\section{Introdução}

A areia é um material de origem mineral finamente dividido em grânulos, composta basicamente de dióxido de silício, forma-se por fragmentação das rochas por erosão, pela ação do vento ou da água. O tamanho dos grãos de areia (agregado miúdo) tem importância nas características dos materiais que a utilizam como componente, como é o caso da construção civil. Segundo Bauer (2015) o agregado é formado por mistura de grãos de extensa gama de tamanhos. É difícil encontrar uniformidade nas dimensões de grãos de areia de mesma categoria, a proporção relativa, em porcentagem, dos diferentes tamanhos de grãos que constituem o agregado é chamado de granulometria, esta composição é obtida através de ensaio laboratorial (Ribeiro, Pinto \& Starling - 2013). A distribuição granulométrica da areia apresenta características mais convenientes para a fabricação de tijolos, pois proporciona uma melhoria na densidade de prensagem da mistura, afetando as propriedades finais do produto. Isso ocorre devido à composição da areia ser um material resistente e inerte, com função apenas de enchimento, favorecendo a liberação de quantidades maiores de cimento para aglomerar com grãos menores do solo (Sá, 2019).

Para garantir a qualidade e segurança das obras realizadas é importante determinar as dimensões das partículas, que pode ser encontrado de todas as formas e tamanhos, a mais importante, do ponto de vista da engenharia, são as partículas pequenas, denominada por agregado miúdo. Um estudo sobre a fragmentação, o peneiramento, a mistura e separações mecânica, análise mineralógica serão efetuadas a para definir qual a granulometria mais adequada a ser utilizada na construção civil. Segundo Caputo (2013) a analise granulométrica, ou seja, a determinação das dimensões das partículas do solo e das proporções relativas em que elas se encontram, é representada, graficamente, pela curva granulométrica, que é traçada por pontos em um diagrama semi-logarítmico, no qual, sobre o eixo das ordenadas as porcentagens, em peso, de material que tem dimensão media menor que a dimensão considerada.

Para a determinação granulométrica do agregado é utilizado a NBR NM 248 - Agregados - Determinação da composição granulométrica, norma que tem o objetivo de prescrever o método para a determinação da composição granulométrica de agregados miúdos e graúdos. Nesse caso, vamos mostrar o ensaio granulométrico do agregado miúdo e verificar a mais adequada para o uso na construção civil. Na falta de ensaio de granulometria nos agregados miúdos, é comum a venda inadequada do agregado com diâmetro inferior ao apropriado a cada finalidade na construção civil.

De acordo com Senna (2003) as técnicas de espectrometria de raios-X baseiam-se nas medidas de emissão, absorção, espalhamento, fluorescência e difração da radiação eletromagnética. Desta forma, apesar da caracterização das amostras ser uma tarefa complicada e trabalhosa, dois ensaios têm tido relevada importância na execução desse papel: a difração de raio-X, 
que permite identificar os argilominerais presentes na amostra, e a fluorescência de raio-X, que têm a função de identificar os elementos químicos presentes. Esses dois métodos, por si só, não apresentam elevada confiabilidade, e, portanto, pode ser necessário o uso de outras técnicas, como a determinação da capacidade da troca de cátions, a análise térmica diferencial, a microscopia eletrônica e a espectrometria de infravermelho. Essas técnicas, se combinadas, podem caracterizar as matériasprimas utilizadas.

Segundo Cortez (2002) nos últimos anos, centenas de empresas da indústria da construção deram início à programas gerenciais de produtividade e qualidade. $\mathrm{O}$ foco principal é reduzir desperdícios, bem como otimizar a gestão e os processos construtivos. A construção civil utiliza como matéria-prima os produtos acabados de outras indústrias. Para que haja um controle de qualidade, o engenheiro responsável pela obra deve certificar-se da qualidade de todos os insumos utilizados durante a fase de construção para garantir que ao fim da obra, seja qual for o produto a ser entregue, terá qualidade e durabilidade.

A proposta apresentada neste artigo terá como ponto de partida ensaios para definição granulométrica do agregado miúdo, florescência de raio X (FRX) e difração de reio X (DRX). Por fim, acredita-se que esta pesquisa dará relevantes contribuições ao meio acadêmico, haja vista que possibilita o conhecimento das origens da deterioração, bem como possa proceder a reparos exigidos, além de contribuir como referência para futuras fontes de pesquisa ao Curso de engenharia Civil.

\section{Revisão Bibliográfica}

A areia é um material de origem mineral finamente dividido em grânulos, composta basicamente de dióxido de silício, forma-se por fragmentação das rochas por erosão, pela ação do vento ou da água, é utilizada nas obras de Engenharia Civil, em aterros, execuções de concretos.

Segundo Bauer (2014) O agregado é formado por mistura de grãos de extensa gama de tamanhos. É difícil encontrar uniformidade nas dimensões de grãos de areia de mesma categoria, a proporção relativa, em porcentagem, dos diferentes tamanhos de grãos que constituem o agregado é chamado de granulometria, (Ribeiro, Pinto \& Starling - 2013) está composição é obtida através de ensaio laboratorial, no qual a amostra do agregado é submetida a uma separação dos grãos por faixas granulométricas, de acordo com a série de peneiras da ABNT, para então serem definidos a dimensão máxima características é o modulo de finura. Esses parâmetros são fundamentais para especificar o emprego dos agregados em concretos. Cabe ressaltar que a composição granulométrica tem influência direta sobre a qualidade desses produtos, principalmente nos aspectos relativos à consistência, a resistência aos esforços mecânicos e a tração.

\subsection{Areia usada em concreto}

Para definir a granulometria ideal para o concreto, apresentamos o ensaio da curva granulométrica, Caputo (2013) segundo a forma da curva podemos distinguir os diferentes tipos de granulometria, o propósito deste ensaio é encontrar a composição granulométrica que dê maior consistência possível, requerendo boa pasta de aglomerante, acarretando economia e aumento da resistência dos concretos.

O tamanho dos grãos de areia (agregado miúdo) tem importância nas características dos materiais que a utilizam como componente, como é o caso do concreto. O agregado miúdo é um material que, no início do desenvolvimento do concreto, é adicionado ao cimento, agregado graúdo e água, para dar-lhe "corpo", tornando-a mais econômica, além de sua influência benéfica quanto à resistência, o tamanho, a densidade e a forma dos seus grãos podem definir várias das características desejadas em um concreto (Petrucci, 2005).

$\mathrm{Na}$ construção civil o concreto é o material mais importante na atualidade, além disso é o segundo material mais consumido pelo homem, na sua composição natural é um material formado por cimento, agregados (graúdo e miúdo) e água, 
sendo que em algumas vezes pode também ser composto por outro elemento que são os aditivos, pode apresentar diversas propriedades que são alteradas em virtude do tipo e quantidade dos componentes envolvidos. Para identificar tais propriedades é necessário que seja feito experimentos utilizando métodos e equipamentos específicos para determinada finalidade, logo o defeito de um desses compostos pode influir, desfavoravelmente, nas características mais importantes do concreto: resistência a compressão, consistência e tração, que podem ocorrer durante a execução em uma ou mais etapas da construção, no controle de qualidade das atividades, na escolha errada dos materiais (Cortez, 2002).

\subsection{Areia usada em argamassa}

Petrucci (2005) define ainda agregado miúdo normal ou corrente como sendo a areia natural quartzosa ou o pedrisco resultante do britamento de rochas estáveis, com tamanhos de partículas tais que no máximo $15 \%$ ficam retidos na peneira de $4,8 \mathrm{~mm}$.

Os agregados usados nas argamassas são os agregados miúdos, que segundo a NBR 7211 (ABNT, 2005), são aqueles cujos grãos passam pela peneira com abertura de malha de $4,75 \mathrm{~mm}$ e ficam retidos na peneira com abertura de malha de 150 $\mu \mathrm{m}$, em ensaio realizado de acordo com a NBR NM 248, com peneiras definidas pela NBR NM ISO 3310.

De acordo com Ripper (1995), deve-se ter grande atenção no uso dos agregados no concreto e nas argamassas, admitindo que o maior volume destes elementos em uma construção é formado por agregados. Em argamassas, especificamente, usa-se areia comum, de grãos médios até grossos, podendo conter um pouco de argila e impurezas, sendo que para emboço (massa grossa), usa-se areia limpa de grãos médios. Já para reboco (massa fina), é recomendado usar areia fina, lavada (limpa e pura). Isso é importante para evitar "estouros" quando a argamassa, no estado endurecido, entrar em contato com a água de chuva ou umidade interna. Na prática o material usado, tanto para emboço quanto para reboco, é o mesmo, sendo que neste é feito o desempenamento, e naquele, usa-se a esponja para os acabamentos.

\subsection{Areia usada em revestimento cerâmico}

O quartzo (areia), forma alotrópica da sílica na temperatura ambiente, é um dos minerais mais puros e abundantes da crosta terrestre. Sua estrutura consiste em uma rede tridimensional de tetraedros conectados em uma estrutura compacta, consistente com sua alta densidade. Os vazios abertos na sua estrutura são tão pequenos que outros átomos não podem entrar, o que contribui para sua alta pureza. As principais fontes de quartzo para a indústria cerâmica são os arenitos e os quartzitos (Ferrari et al., 2005).

O quartzo (areia) desempenha um papel muito importante na cerâmica de revestimento, porque ajusta a plasticidade da massa, promove a etapa de secagem e a fuga de gases durante o processo de queima, garante a estabilidade das peças, regula a viscosidade da fase líquida formada durante a queima e o coeficiente de expansão térmica (Ferrari et al., 2000). Apesar de possuir uma função importantíssima, o quartzo é uma matéria-prima de baixo custo.

Para Albuquerque et al., (2007), o quartzo (areia) atua como preenchimento, sendo a fase estável a temperatura de sinterização, reduzindo a retração, ou seja, desempenha um papel no controle da dilatação e na distorção da peça cerâmica. Também é usado para reduzir a plasticidade da mistura de matérias-primas e aumentar a permeabilidade da peça crua.

\section{Metodologia}

Segundo Filho (2006) "o ato de pesquisar traz em si a necessidade do diálogo com a realidade a qual se pretende investigar e com o diferente, um diálogo dotado de crítica, canalizador de momentos criativos". Nesse sentido, para Demo (2003), em termos cotidianos, pesquisa não é um ato isolado, intermitente, especial, mas atitude processual de investigação diante do desconhecido e dos limites que a natureza e a sociedade nos impõem. A pesquisa de campo aqui descrita aborda 
desde a preparação das amostras de agregado miúdo e a caracterização do mesmo. O tipo de método para a caracterização dos solos tende a proporcionar uma melhor qualidade ao material em estudo. As amostras dos agregados miúdos (areias de construção) foram ensaiadas nos laboratórios: Materiais e Concreto da AESPI e Laboratório de Cerâmica - PPGEM-IFPI.

\subsection{Granulometria dos agregados miúdos}

A distribuição granulométrica da areia apresenta características que proporciona uma melhoria na densidade de prensagem da mistura, afetando as propriedades finais do produto. Isso ocorre devido à composição da areia ser um material resistente e inerte, com função apenas de enchimento, favorecendo a liberação de quantidades maiores de cimento para aglomerar com grãos menores do solo (Carvalho, 2019). O ensaio de composição granulométrica será realizado conforme a norma ABNT NBR 7181:2016, onde o mesmo consiste em separar os grãos das amostras dos agregados miúdos conforme o tamanho, através do peneiramento. Na primeira etapa do ensaio foi realizada a pesagem de $1 \mathrm{~kg}$ das amostras a ser caracterizada e o encaixe das peneiras, encaixadas em ordem crescente de baixo para cima de acordo com a abertura da malha. As amostras passaram por agitação mecânica do conjunto, por 5 minutos, para permitir a separação e classificação dos diferentes tamanhos de grãos das amostras. Será calculada a porcentagem retida em cada peneira. Para a determinação do Módulo de finura, serão somadas as porcentagens retidas acumuladas em massa, nas peneiras de série normal e dividida por 100. Para tal definição será considerada a utilização de peneiras de séries normal e intermediária. $\mathrm{O}$ ensaio realizou-se nas três amostras dos materiais em questão, onde elaborou-se um quadro resumo da composição granulométrica do material de cada uma das amostras.

\subsection{FRX - Ensaio de fluorescência de raios- $x$}

A análise de Fluorescência de Raios X (FRX) é um método de análise qualitativa e quantitativa da composição dos elementos da amostra, pela excitação de átomos e deteç̧ão de seus raios X característicos (Bruker, 2016). Este ensaio é baseado na energia da radiação de fluorescência emitida por um material após sua excitação com Raios-X, tornando possível identificar os elementos químicos presentes. A utilização da técnica de fluorescência de Raios-X - FRX permite uma rápida avaliação qualitativa dos constituintes da matriz. Para este trabalho as amostras coletadas dos agregados miúdos foram peneiradas na peneira $\mathrm{N}^{\circ} 200$ e encaminhadas ao Laboratório de Materiais (LABMAT) no IFPI para ser submetida a uma análise química através da técnica de espectrometria de fluorescência de Raios-X por meio de um equipamento da marca Shimadzu de modelo EDX-700.

\subsection{DRX - Ensaio de difração de raios-x}

A Difratometria de Raios-X (DRX) consiste em uma técnica analítica de caracterização química e estrutural de minerais bastante aplicadas na análise de solos. É o procedimento de laboratório mais comum para determinação da composição mineralógica de solos. A aplicação desse ensaio é fundamental para identificação e caracterização dos compostos cristalinos presentes nos solos (Resende et al., 2005). As análises da difratometria de Raios-X (DRX) foram realizadas no laboratório de Ciências e Engenharia dos Materiais do IFPI e as amostras foram utilizadas em forma de pó.

\section{Resultados e Discussão}

\subsection{Granulometria dos agregados miúdos}

Foram selecionadas $500 \mathrm{~g}$ de cada uma das amostras de areias para ser levada a estufa, onde a mesma permaneceu por 24 horas em uma temperatura de $110^{\circ} \mathrm{C}$. Em seguida realizou-se a análise granulométrica com o objetivo de determinar as dimensões das partículas que constituem a amostra através do peneiramento a seco para obter a separação de partículas sólidas 
em frações de granulometrias diferentes. Com os resultados, é possível determinar a dimensão máxima (Dmáx) do agregado miúdo como sendo a abertura da malha, em milímetros, da peneira que contém uma porcentagem retida acumulada igual ou inferior a 5\%. E também determinar o módulo de finura de um agregado que é calculado pela soma das porcentagens retidas acumuladas em massa, nas peneiras da série normal, dividida por 100. O módulo de finura também serve para comparação entre dois ou mais agregados. Aquele que possuir menor módulo de finura é o material mais fino. A NBR 7211/2009 apresenta valores de módulo de finura para areias consideradas bem graduadas, conforme o Quadro 1 a seguir:

Quadro 1 - Classificação da areia quanto ao módulo de finura.

\begin{tabular}{|l|l|}
\hline Classificação da areia & Módulo de finura \\
\hline Muito fina & 1,39 a 1,70 \\
\hline Fina & 1,71 a 2,11 \\
\hline Média & 2,12 a 3,38 \\
\hline Grossa & 3,39 a 4,02 \\
\hline Areia de praia & 1,39 \\
\hline
\end{tabular}

Fonte: Autores. (2021).

Os materiais foram peneirados para determinar percentual de grãos retidos e passantes como mostra o quadro 2 e 3 , os gráficos das curvas granulométricas estão descritos nas Figuras 1 e 2 representa o gráfico à disposição granulométrica do agregado miúdo.

Quadro 2 - Resultado da granulometria do agregado miúdo.

\begin{tabular}{|c|c|c|c|c|c|}
\hline \multicolumn{2}{|c|}{ PENEIRAS } & \multirow{2}{*}{$\begin{array}{l}\text { PESO } \\
\text { RETIDO } \\
(\mathrm{g})\end{array}$} & \multirow{2}{*}{$\begin{array}{l}\text { PORCENTAGEM } \\
\text { RETIDA }\end{array}$} & \multirow{2}{*}{$\begin{array}{l}\text { PORCENTAGEM } \\
\text { RETIDA } \\
\text { ACUMULADA }\end{array}$} & \multirow[t]{2}{*}{$\begin{array}{l}\text { PORCENTAGEM } \\
\text { PASSANDO }\end{array}$} \\
\hline POL & $\mathrm{mm}$ & & & & \\
\hline $\mathrm{N}^{\circ} 4$ & 4,80 & 6,72 & $0,67 \%$ & $0,67 \%$ & $99,33 \%$ \\
\hline $\mathrm{N}^{\circ} 8$ & 2,40 & 6,67 & $0,67 \%$ & $1,34 \%$ & $98,66 \%$ \\
\hline $\mathrm{N}^{\mathrm{o}} 16$ & 1,20 & 10,62 & $1,06 \%$ & $2,40 \%$ & $97,60 \%$ \\
\hline $\mathrm{N}^{\mathrm{o}} 30$ & 0,60 & 71,48 & $7,15 \%$ & $9,55 \%$ & $90,45 \%$ \\
\hline $\mathrm{N}^{\circ} 50$ & 0,30 & 547,92 & $54,82 \%$ & $64,37 \%$ & $35,63 \%$ \\
\hline$N^{\circ} 100$ & 0,15 & 260,55 & $26,07 \%$ & $90,44 \%$ & $9,56 \%$ \\
\hline \multicolumn{2}{|c|}{ FUNDO } & 95,46 & $9,55 \%$ & $99,99 \%$ & \\
\hline \multicolumn{2}{|c|}{$\overline{\text { TOTAL }}$} & 999,42 & \multicolumn{2}{|c|}{ "MÓDULO DE FINURA } & $1,69 \mathrm{~mm}$ \\
\hline
\end{tabular}


Research, Society and Development, v. 10, n. 14, e420101422295, 2021

(CC BY 4.0) | ISSN 2525-3409 | DOI: http://dx.doi.org/10.33448/rsd-v10i14.22295

Figura 1 - Gráfico da curva granulométrica do agregado miúdo.

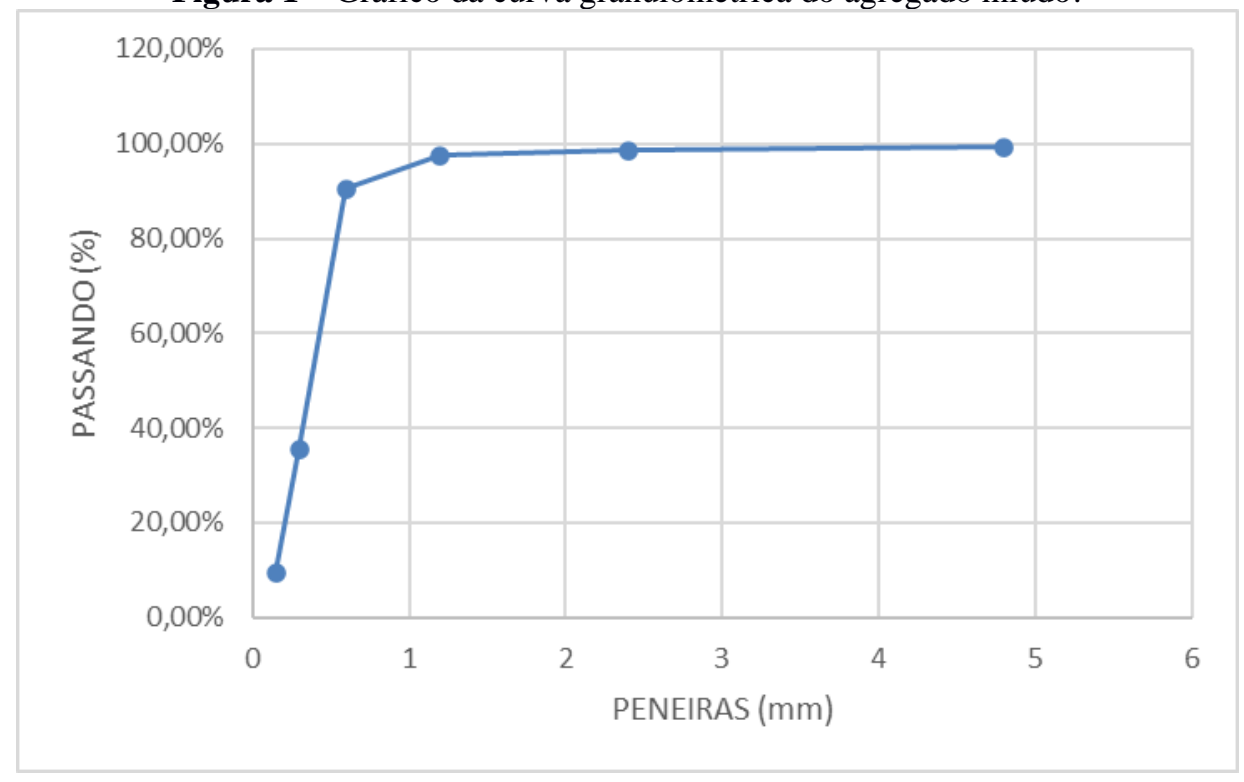

Fonte: Autores (2021).

Com o resultado obtido na análise granulométrica, foram determinados o diâmetro máximo e o módulo de finura do agregado miúdo (areia), os quais são: 1,20 mm e 1,69 mm respectivamente. Com esses resultados, a areia analisada é classificada como uma areia muito fina.

Quadro 3 - Resultado da granulometria do agregado miúdo.

\begin{tabular}{|c|c|c|c|c|c|}
\hline \multicolumn{2}{|c|}{ PENEIRAS } & \multirow{2}{*}{$\begin{array}{l}\text { PESO } \\
\text { RETIDO (g) }\end{array}$} & \multirow{2}{*}{$\begin{array}{l}\text { PORCENTAGEM } \\
\text { RETIDA }\end{array}$} & \multirow{2}{*}{$\begin{array}{l}\text { PORCENTAGEM } \\
\text { RETIDA } \\
\text { ACUMULADA }\end{array}$} & \multirow{2}{*}{$\begin{array}{l}\text { PORCENTAGEM } \\
\text { PASSANDO }\end{array}$} \\
\hline POL & $\mathrm{mm}$ & & & & \\
\hline $\mathrm{N}^{\circ} 4$ & 4,80 & 7,65 & $0,77 \%$ & $0,77 \%$ & $99,23 \%$ \\
\hline $\mathrm{N}^{\circ} 8$ & 2,40 & 19,36 & $1,94 \%$ & $2,71 \%$ & $97,29 \%$ \\
\hline $\mathrm{N}^{\mathrm{o}} 16$ & 1,20 & 58,00 & $5,80 \%$ & $8,51 \%$ & $91,49 \%$ \\
\hline $\mathrm{N}^{\mathrm{o}} 30$ & 0,60 & 323,00 & $32,31 \%$ & $40,82 \%$ & $59,18 \%$ \\
\hline $\mathrm{N}^{\mathrm{o}} 50$ & 0,30 & 342,53 & $34,26 \%$ & $75,08 \%$ & $24,92 \%$ \\
\hline $\mathrm{N}^{\mathrm{o}} 100$ & 0,15 & 187,68 & $18,77 \%$ & $93,85 \%$ & $6,15 \%$ \\
\hline \multicolumn{2}{|c|}{ FUNDO } & 61,60 & $6,16 \%$ & $100,01 \%$ & \\
\hline \multicolumn{2}{|l|}{ TOTAL } & 999,82 & \multicolumn{2}{|c|}{ MÓDULO DE FINURA } & $2,22 \mathrm{~mm}$ \\
\hline
\end{tabular}

Fonte: Autores (2021). 
Figura 2 - Gráfico da curva granulométrica da areia média.

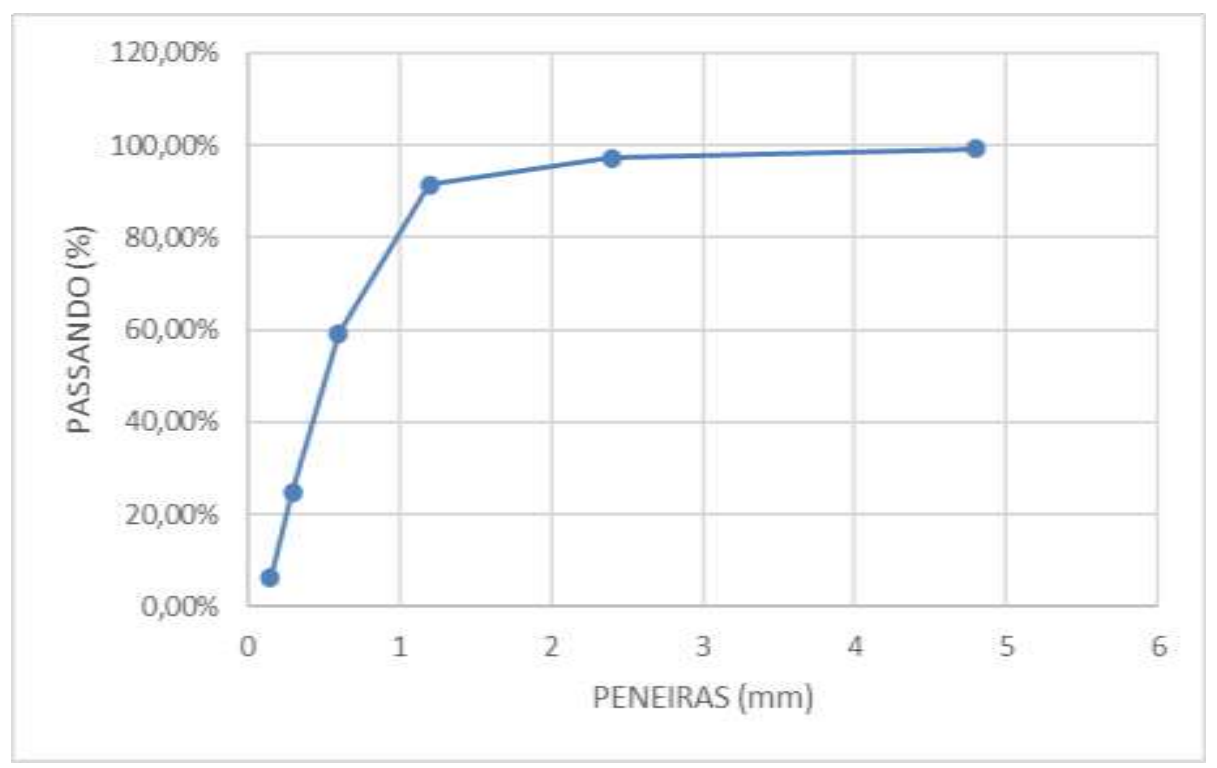

Fonte: Autores (2021).

Com o resultado obtido na análise granulométrica, foram determinados o diâmetro máximo e o módulo de finura do agregado miúdo (areia), os quais são: 2,40 mm e 2,22 mm respectivamente. Com esses resultados, a areia analisada é classificada como uma areia média.

Segundo a ABNT NBR 7211/2009 a curva granulométrica do agregado miúdo pode pertencer tanto a uma zona utilizável quanto a uma zona ótima.

- O módulo de finura da zona ótima varia de 2,20 a 2,90.

- O módulo de finura da zona utilizável inferior varia de 1,55 a 2,20

- $\quad$ O módulo de finura da zona utilizável superior varia de 2,90 a 3,50.

Como pode ser observado nas figuras 32 e 33, os gráficos das amostras analisadas encontram-se dentro dos limites estabelecidos pela norma como zona utilizável inferior para areia fina e zona ótima para areia média.

Com a caracterização dos agregados miúdos coletados é possível verificar pela análise granulométrica a diferença entre as amostras coletadas e classificá-las com segurança devido à determinação do diâmetro máximo e do módulo de finura que os agregados miúdos em estudo se trata de areia fina e areia média, fator de fundamental importância para dar sequência ao desenvolvimento deste trabalho.

\subsection{FRX dos agregados miúdos}

A Fluorescência de Raios-X (FRX) das areias apresentadas tabela 1 são qualitativas, mas, a partir dos resultados, podemos ter uma noção sobre os principais óxidos que constituem as amostras.

Em relação às amostras das areias, é predominantemente composta de óxido de silício $\mathrm{SiO}_{2}(91,76 \%$ e 94,22), porém apresenta uma porcentagem de óxido alumínio $\mathrm{Al}_{2} \mathrm{O}_{3}\left(5,63 \%\right.$ e 3,64\%), a porcentagem de óxido de ferro $\mathrm{Fe}_{2} \mathrm{O}_{3}(0,71 \%$ e $0,77 \%$ ) é pequena, e apresentam apenas traços de outros óxidos os resultados são para areia fina e média respectivamente. 
Tabela 1 - Análise Química por Fluorescência de Raio-x da areia fina e média.

\begin{tabular}{l|c|c|c|c}
\hline \multicolumn{4}{c}{ Análise Química por Fluorescência de Raio-X das areias fina e média $(\%)$} \\
\hline \multicolumn{1}{c}{ Amostra } & $\left(\mathrm{SiO}_{2}\right)$ & $\left(\mathrm{Al}_{2} \mathrm{O}_{3}\right)$ & $\left(\mathrm{Fe}_{2} \mathrm{O}_{3}\right)$ & Outros \\
\hline Areia fina & 91,76 & 5,63 & 0,71 & 1,90 \\
\hline Areia média & 94,22 & 3,64 & 0,77 & 1,39 \\
\hline
\end{tabular}

Fonte: Autores (2021).

Observa-se que a areia fina e areia média, de uma forma geral, existe considerável semelhança na composição química das amostras.

\subsection{DRX dos agregados miúdos}

Nas análises das areias é possível identificar os minerais que as compõem através dos compostos químicos, e o seu grau de cristalinidade através da intensidade dos picos formados por esses compostos. Segundo Marinoni (2012), a intensidade dos picos de difração de raios-X indica a organização cristalina dos minerais, quanto maior o pico menos deformado se encontra o material, tornando mais estável. Os difratogramas de raios-X das areias fina e média estão apresentados na Figura 3 e 4 .

Figura 3 - Gráfico da análise mineralógica da areia fina.

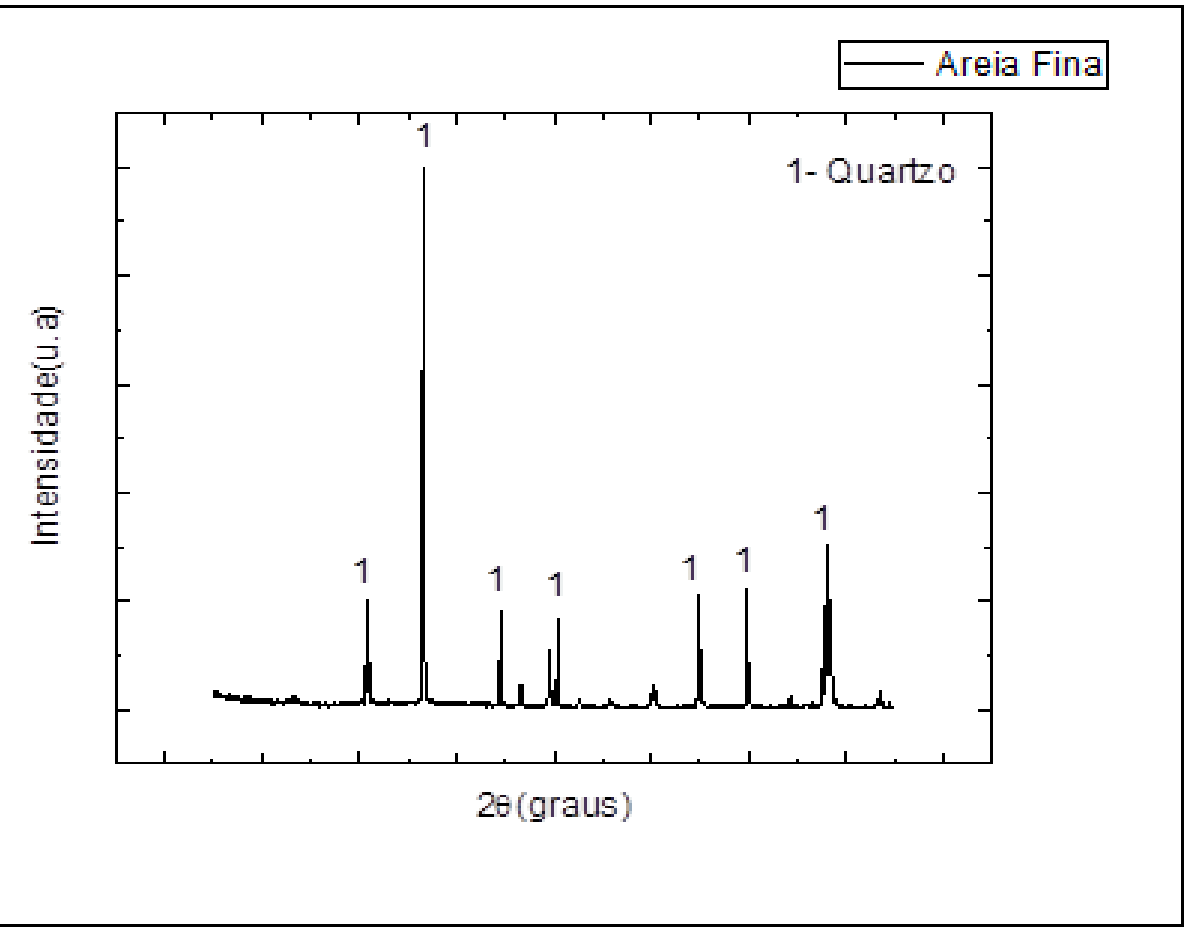

Fonte: Autores (2021). 
Figura 4 - Gráfico da análise mineralógica da areia média.

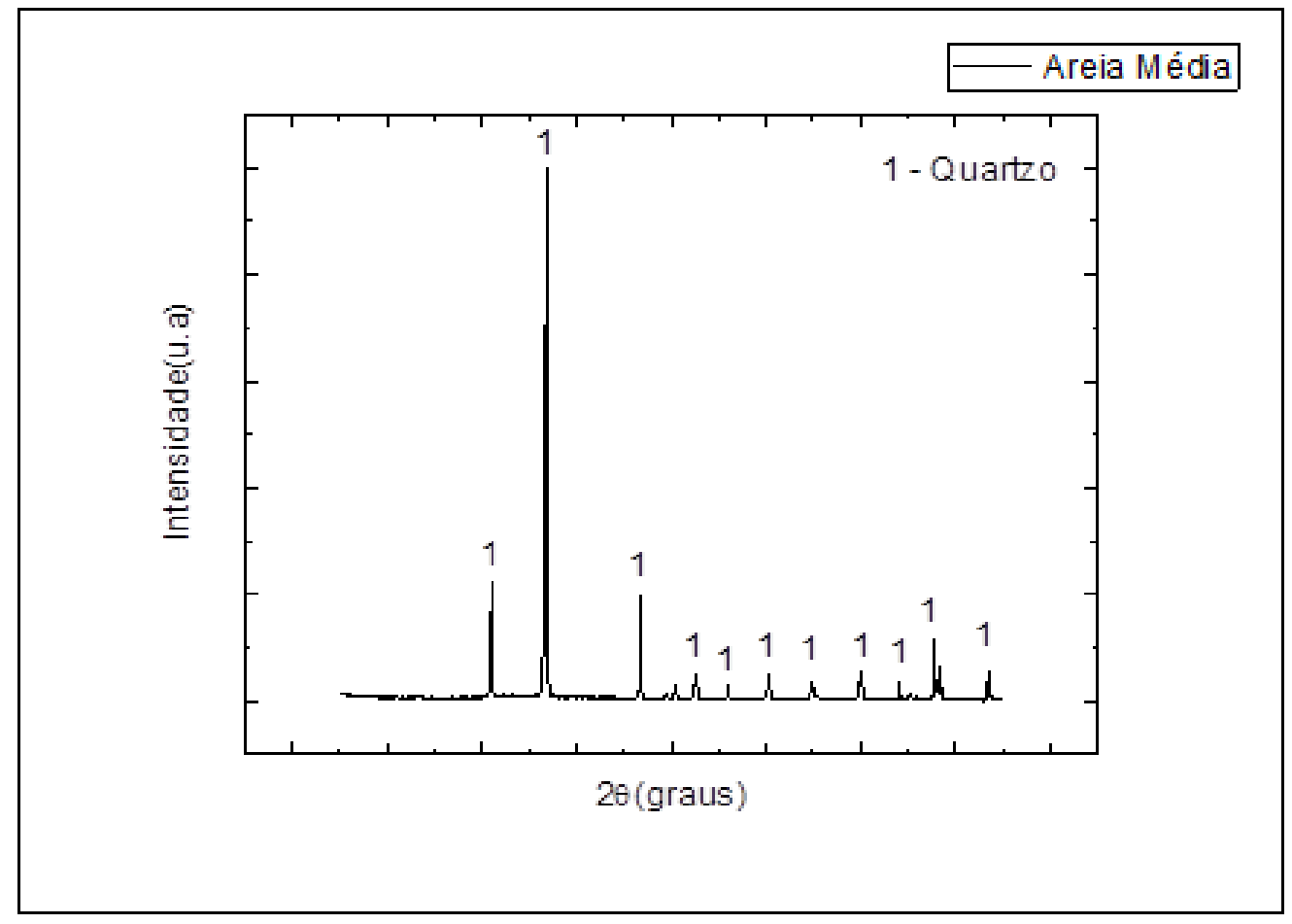

Fonte: Autores (2021).

Observando-se as Figuras 3 e 4, onde se apresentam os gráficos dos difratogramas de raios-X referente às amostras de areia fina e areia média, pode-se constatar que basicamente apresentam uma única fase: quartzo $\left(\mathrm{SiO}_{2}\right)$ corroborando com o resultado da fluorescência de raios-X. Conforme apreciação dos resultados, as areias estudadas são formadas por minerais de estruturas cristalinas bem definidas, desse modo, apresentam-se estáveis, sem riscos de reações patológicas para ser utilizada na construção civil. A Tabela 2 apresenta a análise racional dos agregados miúdos:

Tabela 2 - Concentração das fases cristalinas (\%) dos agregados miúdos.

\begin{tabular}{c|c|c|c|c}
\hline Amostras & Quartzo & Caulinita & Hematita & Outros \\
\hline Areia Fina & $92,5 \%$ & - & - & $7,5 \%$ \\
\hline Areia Média & $95,0 \%$ & - & - & $5,0 \%$ \\
\hline
\end{tabular}

Fonte: Autores (2021).

Para a análise racional as areias determinadas por meio do software QuantFases1.1 demonstraram uma predominância de quartzo.

\section{Conclusão}

Através da caracterização dos agregados miúdos observou-se que os dois tipos de areias encontradas se adequam ao processo produtivo na construção civil. A areia fina pode ser utilizada na produção de argamassas, tintas e compor a produção de revestimentos cerâmicos. As análises de DRX e FRX mostraram a verificação predominância do mineral quartzo em sua análise sendo que o material se encontra, em grande parte em estado amorfo e que os mesmos se enquadram dentro da norma a norma NBR 7211 como agregado miúdo. Para a areia média pode ser utilizada na produção de concreto. Considerando os aspectos da construção civil na produção de argamassas de cimento Portland para assentamento e revestimento de alvenarias, porém, os engenheiros e técnicos da construção civil devem conhecer e avaliar o material disponível para determinar traços 
Research, Society and Development, v. 10, n. 14, e420101422295, 2021

(CC BY 4.0) | ISSN 2525-3409 | DOI: http://dx.doi.org/10.33448/rsd-v10i14.22295

adequados a fim de produzir com propriedades técnicas aceitáveis.

\section{Referências}

ABNT. (2003). NBR NM 248. Agregado - Determinação da Composição Granulométrica.

ABNT. (2001). NBR NM 26. Amostragem de agregados.

ABNT. (2008). ABNT NBR 8522. Determinação do módulo estático de elasticidade à compressão.

ABNT. (2009). NBR NM 7211. Agregados para concreto - Especificação.

Albuquerque, F. R., Santos, I. M. G., Lima, S. J. G., Santos, C. M. R., Soledade, L. E. B., Souza, A. G., \& Martinelli, A. E. (2007). Planejamento Experimental Aplicado à Otimização de massas cerâmicas contendo matérias-primas naturais. Cerâmica, 53, 300-308.

Bauer L. A. F. (2014). Materiais de construção, Ed. LTC, (5a ed.).

Bittencourt, R. M.., Farias L. A., Inácio, J. J., \& Marques, R. A. (2014). Relatório do XIX Programa Interlaboratorial de Ensaios de Concreto, Furnas Centrais Elétricas S.A., à Comissão Técnica de Laboratórios de Ensaios em Construção Civil do Instituto Nacional de Metrologia, Normalização e Qualidade Industrial (INMETRO-CTLE-01), Goiânia.

Bruker (2017). Fluorescência de raios-X (FRX). <https://www.bruker.com>.

Carvalho, R. S. S. (2019). Estudo da viabilidade da utilização da fibra de coco babaçu em formulações de tijolo solo-cimento. Dissertação (Mestrado) Instituto Federal de Educação, Ciência e Tecnologia do Piauí, Piauí.

Caputo, H. P. (2013). Mecânica dos solos e suas aplicações- Fundamentos, Ed. LTC, (6a ed.).

Cortez, A. S. (2002). Custo da não-qualidade na construção civil. IX congresso brasileiro de custos.

Costa, R. M. (1999). Estudo da Durabilidade das Estruturas de Concreto Armado. Belo Horizonte: Universidade Federal de Minas Gerais. 224p. Dissertação (Mestrado em Engenharia de Estruturas - DEES).

Demo, P. (2003). Pesquisa: principio científico e educativo. (10a ed.), Cortez.

Ferrari, K. R., Figueiredo, P. M., Machado, L. A. \& Paschoal, J. O. A. (2000). Transformações das matérias-primas do suporte durante a queima de revestimento cerâmico. Cerâmica industrial, 5.

Filho, J. \& Pe. M. (2002). A família como espaço privilegiado para a construção da cidadania. Franca: Unesp - FHDSS, 2002, (Dissertações e Teses, n.5).

Mehta, K. P., \& Monteiro, P. (1994). Concreto: Estrutura, Propriedades e Materiais. Tradução de P. R. L. Helene et al. São Paulo: Pini. 573p. Original em Inglês: Concrete: Structure, Properties and Materials.

Neville, A.M. (1982). Propriedades do concreto. Pini.

Petrucci, E. G. R. (2005). Concreto de cimento Portland. (14a ed.), Paulon Globo.

Ribeiro, C. C.; Pinto, J. D. S. \& Starling, T. (2013). Materiais de Construção Civil. Ed. UFMG, (4a ed.).

Ripper, E. (1995). Manual prático de materiais de construção. Pini.

Senna, J. A. (2003). Caracterização de Argilas de Utilização na Industria Cerâmica por Espectrometria de Reflectância. 290 p. Dissertação (Mestrado em Geociências) - Instituto de Geociências, Universidade Estadual de Campinas, Campinas. 